\title{
Rural and urban differences in undersupply of buprenorphine provider availability in the United States, 2018
}

Kevin P. Conway ${ }^{1}$, Dalia Khoury ${ }^{2 *}$, Rainer Hilscher ${ }^{2}$, Arnie P. Aldridge², Stephanie J. Parker ${ }^{2}$ and Gary A. Zarkin²

\begin{abstract}
Background: Medications to treat opioid use disorder (OUD) including buprenorphine products are evidence-based and cost-effective tools for combating the opioid crisis. However, limited availability to buprenorphine is pervasive in the United States (US) and may serve to exacerbate the deadly epidemic. Although prior research points to rural counties as especially needy of strategies that improve buprenorphine availability, it is important to investigate the availability of waivered providers according to treatment need as defined by the county-level rate of opioid-overdose deaths (OOD). This study examined differences in buprenorphine provider availability relative to treatment need among rural and urban counties in the US.

Methods: Buprenorphine provider availability relative to need in each county was defined as the number of waivered providers divided by the rate of OODs (i.e., number of OODs/100,000 population), according to 2018 data. Counties with ratios in the bottom tertile of their state were classified as buprenorphine undersupplied. We estimated logit models to statistically test the association of rurality and state main effects and their interaction terms (independent variables) and the county classified as buprenorphine undersupplied (dependent variable).

Results: A total of 38 states and 2595 counties had sufficient non-suppressed data to remain in the analysis. A larger percent of urban counties (36.43\%) than rural counties (32.01\%) were classified as buprenorphine undersupplied ( $p$ $=0.001)$. The likelihood of a rural county being undersupplied varied considerably by state (Chi Square $=82.88, p$ $=0.000$ ). All states with significant $(p<0.05$ or $p<0.10)$ interaction terms showed lower likelihood of buprenorphine undersupply in rural counties.
\end{abstract}

Conclusions: The rural-urban distribution in undersupply of waivered buprenorphine providers relative to need varied markedly by state. Strategies for improving access to buprenorphine-waivered providers should be state-centric and informed by county-specific indicators of need.

Keywords: Buprenorphine, Treatment access, Opioids, Medication for opioid use disorder

\section{Background}

The United States (US) continues to battle an opioid crisis that is constantly shifting and may be worsened by Coronavirus disease 2019 (COVID-19) [1, 2]. Recent

*Correspondence: dkhoury@rti.org

${ }^{2}$ Research Triangle Institute International, , Research Triangle Park, NC, USA

Full list of author information is available at the end of the article national data estimate that 49,860 Americans died from an opioid-related overdose in 2019 ( 137 per day), fueled largely by the use of synthetic opioids such as illicitly manufactured fentanyl [3]. Medications to treat opioid use disorder (OUD) including buprenorphine products approved by the Food and Drug Administration (FDA) are evidence-based and cost-effective tools for combating the opioid crisis [4-6]. However, limited availability original author(s) and the source, provide a link to the Creative Commons licence, and indicate if changes were made. The images or other third party material in this article are included in the article's Creative Commons licence, unless indicated otherwise in a credit line to the material. If material is not included in the article's Creative Commons licence and your intended use is not permitted by statutory regulation or exceeds the permitted use, you will need to obtain permission directly from the copyright holder. To view a copy of this licence, visit http://creativecommons.org/licenses/by/4.0/. The Creative Commons Public Domain Dedication waiver (http://creativeco mmons.org/publicdomain/zero/1.0/) applies to the data made available in this article, unless otherwise stated in a credit line to the data. 
to buprenorphine is pervasive in the US and may serve to exacerbate the deadly epidemic.

Under the Drug Addiction Treatment Act of 2000, the FDA requires physicians and other healthcare providers to obtain waivers to prescribe buprenorphine [7]. Studies show that availability to buprenorphine-waivered providers is especially limited in rural counties. For example, Rosenblatt et al. [8] reported that most physicians with a DEA waiver practice in urban counties, and Andrilla et al. [9] found that only $44 \%$ of rural counties across the US have a waivered provider. Similarly, Dick et al. [10] reported that $29.8 \%$ of rural residents live in a county without a single waivered provider, compared with $2.2 \%$ of residents living in urban counties. Although the number of waivered providers has increased over time in areas with elevated risk of opioid-overdose deaths (OODs) [10,11], the rate of growth in nonmetropolitan and rural counties lags markedly behind urban counties [11]. Results from these studies point to nonurban counties as especially needy of strategies that improve buprenorphine availability.

Beyond the presence of buprenorphine-waivered providers by urbanicity (or rurality), it is important to investigate the availability of waivered providers according to treatment need as defined by the county-level OOD rate. Taking such an approach, Haffajee et al. [12] reported that rural counties had waivered provider rates (in 2017) that were similar to the national rate (pooled from 2015 to 2017), perhaps due to an increase in OODs in urban areas during the study period. Although this study casts doubt on rurality as a risk factor for unmet treatment need, it investigated main effects (of urbanicity) without examining potential differences between urban and rural counties within and across states. Given the observation that OODs vary considerably by county even within specific states [3] and the vital role that individual states and local governments play in combating the opioid crisis, it is critical to examine within-state patterns of buprenorphine availability relative to need to determine whether there is sufficient capacity to address the opioid epidemic locally. The purpose of this study is to examine ruralurban differences in buprenorphine provider availability relative to treatment need across states and counties in the US.

\section{Methods}

We obtained 2018 mortality data from the Multiple Cause of Death database from Centers for Disease Control and Prevention (CDC) WONDER [3]. Drug overdose deaths were classified using the 10th revision of International Classification of Diseases, based on the underlying cause-of-death codes X40-X44 (unintentional), X60-X64 (suicide), X85 (homicide), or Y10-Y14 (undetermined intent). Deaths with the following codes were considered OODs: opium (T40.0); heroin (T40.1); natural and semisynthetic opioids (T40.2); methadone (T40.3); synthetic opioids other than methadone (T40.4); and other unspecified narcotics (T40.6). For counties with suppressed OOD counts (i.e., fewer than 10; $\mathrm{N}=2400$ ), we imputed counts by summing across the non-suppressed counties within a state, subtracting the non-suppressed total from the state's overall total (obtained from CDC WONDER published tables), and dividing the difference by the number of suppressed counties in the state.

Information on buprenorphine-waivered prescribers came from the 2018 Drug Enforcement Administration's (DEA) Active Controlled Substances Act Registrants database. Buprenorphine provider availability relative to need in each county was defined as the number of waivered providers divided by the rate of OODs (i.e., number of OODs/1,00,000 population) in 2018. Counties with ratios in the bottom tertile of their state were classified as buprenorphine undersupplied. We classified each county as rural (micropolitan and non-core) or urban using US census definitions.

Exclusion criteria for states included having fewer than 5 non-suppressed counties (Alaska, Delaware, District of Columbia, Hawaii, Idaho, Iowa, Montana, South Dakota, and Wyoming) and lacking rural counties (New Jersey and Rhode Island) as defind above. We further excluded Maryland and Connecticut from the statistical model due to perfect prediction in the model. A total of 38 states and 2595 counties remained in the analysis.

To statistically test the association of rurality and state (independent variables) and the county classified as buprenorphine undersupplied (dependent variable), we estimated a logit model that included a county's rural status, individual state indicators, and interaction terms indicating whether the county is in a given state and is also a rural county.

\section{Results}

For the 2595 counties in the analysis, the rate of buprenorphine providers (per 1,00,000 population) averaged 1.4 (SD =2.6) and ranged from 0 to 39.1. The rate of OODs (per 1,00,000 population) averaged 17.98 $(\mathrm{SD}=24.96)$ and ranged from 0.29 to 487.37 ; the number of OODs averaged 15.31 ( $\mathrm{SD}=50.26$ and ranged from 0.61 to 1007 . The average rate of buprenorphine provider availability relative to need was 13.9 $(\mathrm{SD}=24.7)$ and ranged from 0 to 288.7. A larger percent of urban counties (36.43\%) than rural counties (32.01\%) were classified as buprenorphine undersupplied ( $\mathrm{p}=0.001$ ). The Fig. 1 displays the percentage of a state's rural (in red) and urban (in blue) counties that were buprenorphine undersupplied in 2018. Across the 


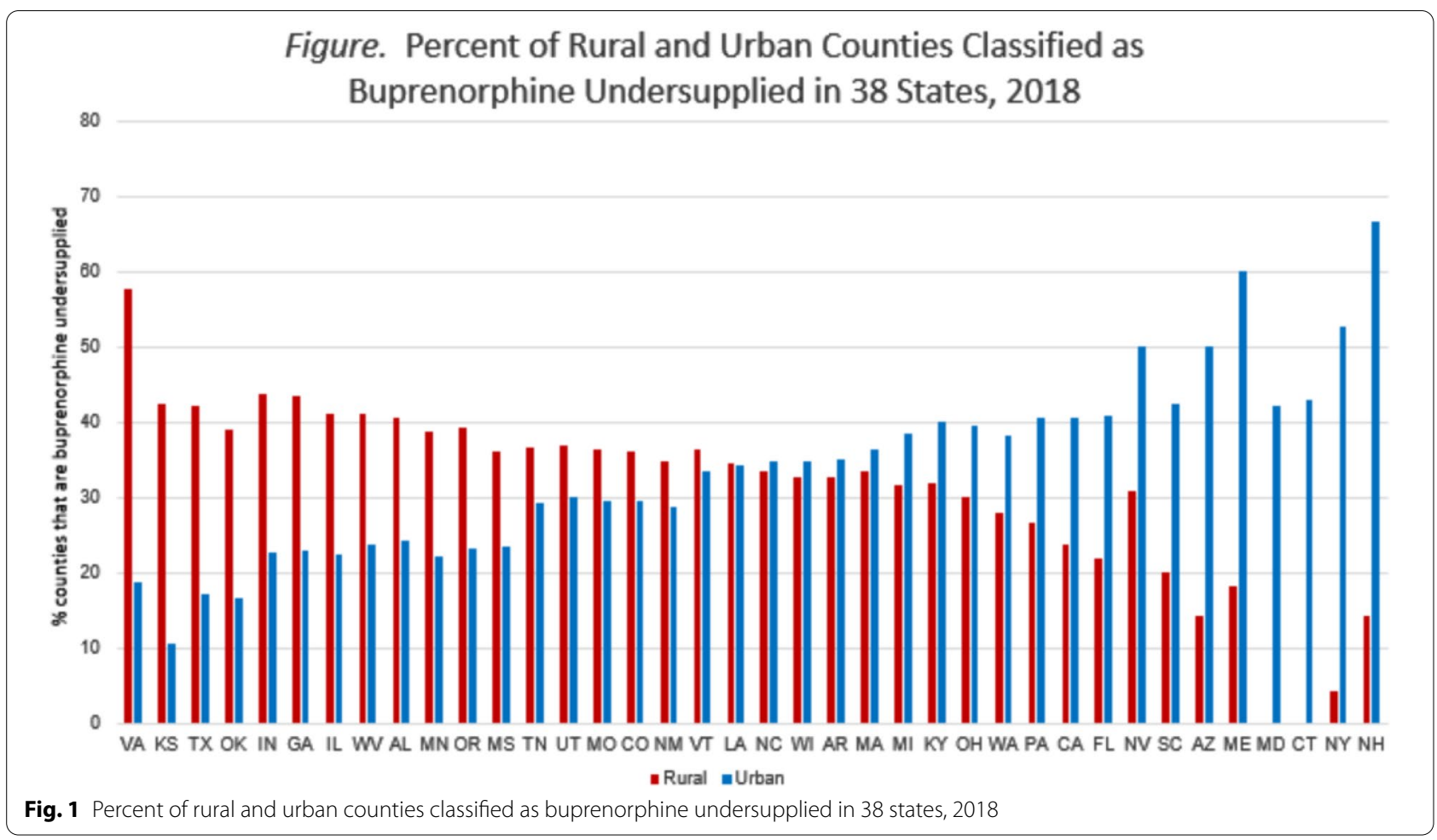

38 states, undersupply concentrated in rural counties in roughly half of the states and in urban counties in the remaining half.

The Table 1 shows the results of the logit model. Being a rural county was not systematically associated with buprenorphine undersupply $(\mathrm{p}=0.164)$ across the 38 states. We rejected the null hypothesis of equal state-rural interactions $(\mathrm{p}<0.000)$, indicating that the likelihood of a rural county being buprenorphine undersupplied varied significantly by state. Inspection of the state-by-rural interaction results shows that all four states with significant $(\mathrm{p}<0.05)$ interaction terms showed lower likelihood of buprenorphine undersupply in rural counties. For example, in Florida, the odds ratio $(\mathrm{OR})$ for the interaction term $(0.187, \mathrm{p}=0.038)$ indicates that rural counties (compared to urban counties) were significantly less likely to be buprenorphine undersupplied. Specifically, rural counties in Florida were $81.3 \%$ less likely than urban counties to be buprenorphine undersupplied. For the remaining three states, this difference was $98.2 \%$ in New York, $93.1 \%$ in Maine, and $84.1 \%$ in South Carolina. Five additional states with borderline significant $(\mathrm{p}<0.10)$ interaction terms also showed lower likelihood of buprenorphine undersupply in rural counties. The difference was $92.2 \%$ in Arizona, 78.6\% in California, 96.1\% in New Hampshire, $69.3 \%$ in Ohio, and $75.1 \%$ in Pennsylvania.

\section{Conclusions}

Previous studies identified rurality as a common risk factor for the undersupply of waivered providers for the treatment of OUD [8-10]. In contrast, the current study shows that the rural-urban distribution in undersupply of waivered buprenorphine providers relative to need varied markedly by state. Further, our results show that, in states with significant rural-urban differences, buprenorphine undersupply relative to need was less likely in rural counties. The lower likelihood of buprenorphine undersupply in rural counties was considerable and ranged from 81.3 to $98.2 \%$ (at the $\mathrm{p}<0.05$ level) and from 69.3 to $96.1 \%$ (at the $\mathrm{p}<0.10$ level).

Our study has limitations. There is no standard measure of buprenorphine undersupply, and our measure is relative to treatment need as defined by OOD rate within each county. Further, the DEA data on buprenorphinewaivered prescribers do not inform about the actual provision of buprenorphine, including whether providers are actively prescribing at or below their capacity. Indeed, many providers do not prescribe up to capacity $[13,14]$ due to a variety of reasons that are both pragmatic (e.g., time, reimbursement) and attitudinal (e.g., beliefs about agonist treatment) [15]. The DEA data also do not provide information on the quality of care. Additionally, athough we used the most recent data for buprenorphinewaivered prescribers, they remain somewhat outdated. A 
Table 1 Model estimates for being a buprehorphine undersupply county in 38 states, 2018

\begin{tabular}{|c|c|c|c|c|c|c|}
\hline \multirow[t]{3}{*}{ Covariates } & \multicolumn{6}{|c|}{ All states-linear probability model } \\
\hline & \multicolumn{2}{|l|}{ Main effects } & \multirow[t]{2}{*}{$p$ value } & \multicolumn{3}{|c|}{ Interactions of state $\times$ rural } \\
\hline & Odds ratio & $95 \% \mathrm{Cl}$ & & Odds ratio & $95 \% \mathrm{Cl}$ & $\mathrm{p}$ value \\
\hline Constant & $0.318^{* * *}$ & $0.136-0.745$ & 0.008 & & & \\
\hline Rural & 2.143 & $0.732-6.275$ & 0.164 & & & \\
\hline$A Z$ & 3.143 & $0.618-15.983$ & 0.168 & $0.078^{*}$ & $0.005-1.216$ & 0.069 \\
\hline AR & 1.692 & $0.484-5.920$ & 0.410 & 0.422 & $0.092-1.932$ & 0.266 \\
\hline CA & 2.143 & $0.732-6.275$ & 0.164 & $0.214^{*}$ & $0.043-1.071$ & 0.061 \\
\hline $\mathrm{CO}$ & 1.310 & $0.341-5.033$ & 0.695 & 0.635 & $0.127-3.180$ & 0.580 \\
\hline $\mathrm{FL}$ & 2.176 & $0.768-6.166$ & 0.144 & $0.187^{* *}$ & $0.039-0.909$ & 0.038 \\
\hline GA & 0.937 & $0.342-2.570$ & 0.900 & 1.206 & $0.336-4.327$ & 0.774 \\
\hline $\mathrm{IL}$ & 0.912 & $0.295-2.822$ & 0.874 & 1.116 & $0.275-4.536$ & 0.878 \\
\hline IN & 0.924 & $0.306-2.791$ & 0.889 & 1.234 & $0.302-5.035$ & 0.769 \\
\hline KS & 0.370 & $0.068-2.013$ & 0.250 & 2.914 & $0.450-18.860$ & 0.262 \\
\hline KY & 2.095 & $0.707-6.212$ & 0.182 & 0.326 & $0.085-1.256$ & 0.103 \\
\hline LA & 1.640 & $0.546-4.928$ & 0.378 & 0.471 & $0.106-2.095$ & 0.323 \\
\hline ME & 4.714 & $0.650-34.194$ & 0.125 & $0.069^{* *}$ & $0.005-0.921$ & 0.043 \\
\hline MA & 1.796 & $0.403-8.004$ & 0.443 & 0.408 & $0.022-7.445$ & 0.545 \\
\hline $\mathrm{Ml}$ & 1.964 & $0.615-6.273$ & 0.254 & 0.345 & $0.081-1.463$ & 0.149 \\
\hline $\mathrm{MN}$ & 0.898 & $0.259-3.115$ & 0.865 & 1.027 & $0.228-4.620$ & 0.973 \\
\hline MS & 0.967 & $0.237-3.950$ & 0.963 & 0.851 & $0.166-4.362$ & 0.846 \\
\hline $\mathrm{MO}$ & 1.310 & $0.425-4.038$ & 0.639 & 0.637 & $0.160-2.534$ & 0.522 \\
\hline NV & 3.143 & $0.371-26.632$ & 0.294 & 0.207 & $0.017-2.596$ & 0.222 \\
\hline $\mathrm{NH}$ & 6.286 & $0.492-80.274$ & 0.157 & $0.039^{*}$ & $0.001-1.138$ & 0.059 \\
\hline NM & 1.257 & $0.198-7.976$ & 0.808 & 0.618 & $0.074-5.150$ & 0.656 \\
\hline NY & $3.492^{* *}$ & $1.207-10.107$ & 0.021 & $0.018^{* * *}$ & $0.002-0.193$ & 0.001 \\
\hline NC & 1.676 & $0.590-4.766$ & 0.333 & 0.437 & $0.113-1.700$ & 0.233 \\
\hline $\mathrm{OH}$ & 2.050 & $0.702-5.981$ & 0.189 & $0.307^{*}$ & $0.076-1.236$ & 0.097 \\
\hline OK & 0.629 & $0.140-2.827$ & 0.545 & 1.491 & $0.266-8.342$ & 0.650 \\
\hline OR & 0.943 & $0.201-4.423$ & 0.941 & 1.000 & $0.153-6.531$ & 1.000 \\
\hline PA & 2.143 & $0.732-6.275$ & 0.164 & $0.249^{*}$ & $0.056-1.112$ & 0.069 \\
\hline SC & 2.305 & $0.728-7.300$ & 0.156 & $0.159^{* *}$ & $0.028-0.889$ & 0.036 \\
\hline TN & 1.300 & $0.440-3.847$ & 0.635 & 0.649 & $0.162-2.601$ & 0.542 \\
\hline TX & 0.647 & $0.232-1.807$ & 0.406 & 1.653 & $0.470-5.810$ & 0.433 \\
\hline UT & 1.347 & $0.272-6.658$ & 0.715 & 0.635 & $0.089-4.523$ & 0.650 \\
\hline VT & 1.571 & $0.123-20.069$ & 0.728 & 0.533 & $0.029-9.724$ & 0.671 \\
\hline VA & 0.725 & $0.262-2.010$ & 0.537 & 2.758 & $0.728-10.441$ & 0.135 \\
\hline WA & 1.934 & $0.568-6.581$ & 0.291 & 0.292 & $0.052-1.646$ & 0.163 \\
\hline WV & 0.982 & $0.263-3.663$ & 0.979 & 1.045 & $0.207-5.291$ & 0.957 \\
\hline WI & 1.664 & $0.515-5.379$ & 0.395 & 0.427 & $0.097-1.872$ & 0.259 \\
\hline Observations & 2595 & & & 2595 & & \\
\hline R-squared & 0.004 & & & 0.041 & & \\
\hline $\begin{array}{l}\text { Joint Chi-squared test of } \\
\text { equality all rural } \times \text { state } \\
\text { coefficients }\end{array}$ & & & & 82.88 & & 0.000 \\
\hline $\begin{array}{l}\text { Joint Chi-squared test of } \\
\text { equality of rural } \times \text { state } \\
\text { coefficients for } 10 \text { states } \\
\text { with the highest per capita } \\
\text { fatal opioid overdose rate } \\
\text { (KY, MA, ME, MO, NH, NM, } \\
\text { OH, PA, TN, and WV) }\end{array}$ & & & & 10.36 & & 0.322 \\
\hline
\end{tabular}

All models use Robust Standard Errors

$\mathrm{AL}$ is the reference state

${ }^{* * *} \mathrm{p}<0.01,{ }^{* *} \mathrm{p}<0.05,{ }^{*} \mathrm{p}<0.1$ 
substantial proportion of counties had suppressed OOD data requiring imputation that may undercount or overcount OODs. Exclusion criteria reduced our sample to 38 states, thereby limiting generalizability. Finally, more research is needed on ways to increase buprenorphine provision for the treatment of OUDs, and whether doing so impacts the opioid epidemic.

In sum, our findings suggest that actions and reallocation of resources to improve availability of buprenorphine to treat OUDs must be done on a state-by-state basis that accounts for county-specific indicators of availability relative to need. To the extent that COVID-19 has exacerbated the opioid crisis [2] and will disproportionately impact individuals with OUD by interrupting availability to medication for OUD [1], coordinated statecounty action is urgently warranted.

\section{Abbreviations}

CDC WONDER: Centers for Disease Control and Prevention Wide-ranging ONline Data for Epidemiologic Research; COVID-19: Coronavirus disease 2019; DEA: Drug Enforcement Administration; FDA: Food and Drug Administration; OUD: Opioid use disorder; OOD: Opioid overdose deaths.

\section{Acknowledgements}

Not applicable.

\section{Authors' contributions}

KPC, DK, and GZ contributed to the study concept and design. All authors contributed to the acquisition, analysis, or interpretation of data. APA and RH did the statistical analysis. KPC, DK, GZ, and APA drafted the manuscript. All authors critically revised the manuscript for important intellectual content. DK and SJP provided administrative, technical, or material support. GZ and KPC obtained funding and provided supervision. All authors read and approved the final manuscript.

\section{Funding}

This research was supported by funding from the Research Triangle Institute (RTI) Opioid Strategic Investment Fund. The funder had no role in the design and conduct of the study; collection, management, analysis, and interpretation of the data; preparation, review, or approval of the manuscript; and decision to submit the manuscript for publication. This study was also supported in part by the Intramural Research Program of the National Institute of Mental Health (ZIAMH002953). The views and opinions expressed in this paper are those of the authors and should not be construed to represent the views of any of the sponsoring organizations, agencies, or US Government.

\section{Availability of data and materials}

Data and materials can be made available by contacting corresponding author (DK).

\section{Declarations}

Ethics approval and consent to participate

This study consisted of secondary analyses; no individuals were involved. As data do not include any personally identifiable information, Institutional Review Board approval was not required.

\section{Consent for publication}

Not applicable.

\section{Competing interests}

Authors report no competing interests.

\section{Author details}

${ }^{1}$ National Institute of Mental Health, Bethesda, MD, USA. ${ }^{2}$ Research Triangle Institute International, , Research Triangle Park, NC, USA.

Received: 28 December 2020 Accepted: 2 December 2021

Published online: 31 January 2022

\section{References}

1. Becker WC, Fiellin DA. When epidemics collide: coronavirus disease 2019 (COVID-19) and the opioid crisis. Ann Intern Med. 2020;173(1):59-60. https://doi.org/10.7326/M20-1210.

2. Khoury D, Preiss A, Geiger P, Anwar M, Conway K. Increases in naloxone administrations by Emergency Medical Services providers during the COVID-19 pandemic: retrospective time series study. JMIR Public Health Surveill. 2021;7(5):e29298. https://doi.org/10.2196/29298.

3. Centers for Disease Control and Prevention, National Center for Health Statistics. Multiple cause of death 1999-2018 on CDC WONDER online database. https://www.cdc.gov/drugoverdose/data/statedeaths.html. Accessed 28 Jun 2020.

4. Larochelle MR, Bernson D, Land T, Stopka TJ, Wang N, Xuan Z, et al. Medication for opioid use disorder after nonfatal opioid overdose and association with mortality: a cohort study. Ann Intern Med. 2018;169(3):137-45. https://doi.org/10.7326/M17-3107.

5. Murphy SM, McCollister KE, Leff JA, Yang X, Jeng PJ, Lee JD, et al. Costeffectiveness of buprenorphine-naloxone versus extended-release naltrexone to prevent opioid relapse. Ann Intern Med. 2019;170(2):90-8. https://doi.org/10.7326/M18-0227.

6. Sordo L, Barrio G, Bravo MJ, Indave Bl, Degenhardt L, Wiessing L, et al. Mortality risk during and after opioid substitution treatment: systematic review and meta-analysis of cohort studies. BMJ. 2017;357: j1550. https:// doi.org/10.1136/bmj.j1550

7. Volkow ND, Jones EB, Einstein EB, Wargo EM. Prevention and treatment of opioid misuse and addiction: a review. JAMA Psychiat. 2019;76(2):208-16. https://doi.org/10.1001/jamapsychiatry.2018.3126.

8. Rosenblatt RA, Andrilla CHA, Catlin M, Larson EH. Geographic and specialty distribution of US physicians trained to treat opioid use disorder. Ann Fam Med. 2015;13(1):23-6. https://doi.org/10.1370/afm.1735.

9. Andrilla CHA, Moore TE, Patterson DG, Larson EH. Geographic distribution of providers with a DEA waiver to prescribe buprenorphine for the treatment of opioid use disorder: a 5-year update: distribution of providers with a DEA waiver. J Rural Health. 2019;35(1):108-12. https://doi.org/10. 1111/jrh.12307.

10. Dick AW, Pacula RL, Gordon AJ, Sorbero M, Burns RM, Leslie D, et al. Growth in buprenorphine waivers for physicians increased potential access to opioid agonist treatment, 2002-11. Health Aff. 2015;34(6):102834. https://doi.org/10.1377/hlthaff.2014.1205.

11. McBain RK, Dick A, Sorbero M, Stein BD. Growth and distribution of buprenorphine-waivered providers in the United States, 2007-2017. Ann Intern Med. 2020;172(7):504-6. https://doi.org/10.7326/M19-2403.

12. Haffajee RL, Lin LA, Bohnert ASB, Goldstick JE. Characteristics of US counties with high opioid overdose mortality and low capacity to deliver medications for opioid use disorder. JAMA Netw Open. 2019;2(6): e196373. https://doi.org/10.1001/jamanetworkopen.2019.6373.

13. Duncan A, Anderman J, Deseran T, Reynolds I, Stein BD. Monthly patient volumes of buprenorphine-waivered clinicians in the US. JAMA Netw Open. 2020;3(8):e2014045.

14. Stein BD, Sorbero M, Dick AW, Liccardo-Pacula R, Burns RM, Gordon AJ. Physician capacity to treat opioid use disorder with buprenorphineassisted treatment. JAMA. 2016. https://doi.org/10.1001/jama.2016.10542.

15. Huhn AS, Dunn KE. Why aren't physicians prescribing more buprenorphine? J Subst Abuse Treat. 2017. https://doi.org/10.1016/j.jsat.2017.04. 005.

\section{Publisher's Note}

Springer Nature remains neutral with regard to jurisdictional claims in published maps and institutional affiliations. 